$\xi=-1$

\title{
Examining the Predictors of Mobile Addiction: Some Insights from Malaysia
}

\author{
Norazah Mohd Suki ${ }^{1}$, Norbayah Mohd Suki² \\ ${ }^{1}$ Labuan Faculty of International Finance, Universiti Malaysia Sabah, 87000 F.T. Labuan, Malaysia \\ ${ }^{2}$ Faculty of Computing and Informatics, Universiti Malaysia Sabah, 87000 F.T. Labuan, Malaysia
}

\begin{abstract}
This research aims to investigate the predictors of mobile addiction. The data was analyzed using Partial Least Square-Structural Equation Modelling (PLS-SEM) approach supported by Smart-PLS 2.0 to assess the hypothesis in the research model. The PLS-SEM technique revealed that there was a strong correlation between social networking sites (SNS) intensity and mobile addiction. Users have positively expressed that visiting SNS is part of their everyday activity as they tend to check their SNS almost every day. They have this perception that they will feel out of touch when they do not log into their SNS for a day. In addition, they feel as if they are part of the community of SNS on campus. Those with many SNS accounts have a strong tendency to install and use mobile social networking apps on their mobile phones to connect and communicate with others. These heavy users frequently use their mobile phone to log into their social network via preferred social networking apps and actively use it to check the SNS. The direction for future research is also presented.
\end{abstract}

Keywords: Mobile Addiction, Social Networking Services (SNS), SNS Intensity, Partial Least Square-Structural Equation Modelling (PLS-SEM)

\section{Introduction}

A dramatic evolution of mobile traffic on mobile applications (mobile apps) such as Facebook app is an accessible avenue for individuals to get connected with virtual communities, friends and family members in a real-time access from anywhere and at any time of the day. In actual fact, there are more than 2.07 billion monthly active Facebook users for Q3 2017². Their active participation is significant, and this trend had changed the cultural norms and behavior of the consumers. This extreme usage of mobile phone leads to mobile phone addiction which has resulted in negative effects ${ }^{2}$, and health risks such as sleep time disruption and brain damage ${ }^{3}$.

Furthermore, He et al. ${ }^{4}$ stated that the rate of mobile phone addiction among young people was higher than $30 \%$. In a different study, Lopez-Fernandez and Freixa-Blanxart ${ }^{5}$ discovered that the incidence of mobile phone addiction climbed up to $38 \%$ across cultures and societies with $62 \%$ possible addiction. These figures triggered detrimental consequences such as academic failure, lack of interpersonal skills, dejection, and fretfulness among mobile phone users ${ }^{6-7}$.

However, empirical studies related to mobile phone addiction are scarce $^{8}$, particularly pertaining to developing country, and little is known about the predictors of mobile addiction. Hence, the goal of this research is to investigate the predictors of mobile addiction.

\section{Literature review}

Social networking services is referred to as "web-based services that allow individuals to (1) construct a public or semi-public profile within a bounded system, (2) articulate a list of other users with whom they share a connection, and (3) view and traverse their list of connections and those made by others within the system"9. However, excessive dependence on mobile phone will result in mobile phone addiction where individuals tended to suffer from discomfort and annoyance when some people are unreachable through their mobile phone ${ }^{10}$.

On the other hand, social networking sites (SNS) intensity is referred to "the frequency of use and time spent on social networking services"11. Mobile phone addiction causes an individual to develop a high sense of attachment and interaction to a group with strong growth of friendship quality ${ }^{12}$ which may affect their friends' lives ${ }^{13-14}$. Indeed, it has been reported that when there is a higher concentration of SNS, individuals have a tendency to receive more benefits from their online companionships ${ }^{12}$.

Besides, mobile addiction causes negative consequences where it lessens human physical, psychological and social function, as well as conveys negative impacts and health risks such as stress, social extroversion, irregular sleeping time and brain damage ${ }^{3,15}$. In a similar vein, earlier scholars affirmed that depression, anxiety and stress are associated with mobile phone addiction ${ }^{16-17}$. Another study on the link between mobile phone addiction and shyness and among Chinese young adults, Han et al. ${ }^{18}$ found a significant positive link between shyness, attachment anxiety, and mobile phone addiction.

In line with the research above, this study puts forward the following hypotheses:

H1: SNS intensity has a positive impact on users' mobile addiction

H2: SNS intensity has a positive impact on the use of the SNS mobile apps

H3: The Use of SNS mobile apps has a positive impact on users' mobile addiction 


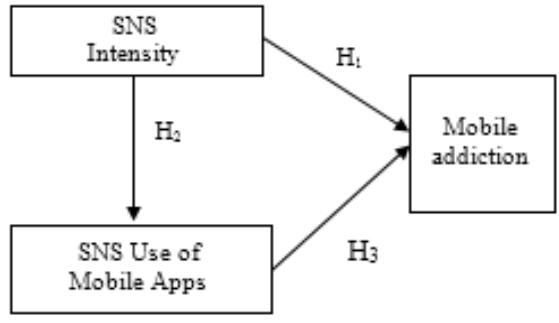

Figure 1: Proposed Theoretical Framework

\section{Methodology}

A quantitative research design was employed via the dissemination of a structured self-administered questionnaire to 300 students in a public higher learning institution in the Federal Territory of Labuan, Malaysia. The respondents were restricted to university students who own at least one mobile phone. After excluding the questionnaires that had not been correctly filled-up, 250 usable responses were attained for further analysis (valid response rate of $83 \%)$.

Section A of the three-section questionnaire covered the demographic characteristics of the respondents. Questions related to respondents' experiences of mobile phone usability were presented in Section B. The final section of the questionnaire, Section C, enclosed fifteen measurement items such as mobile addiction (5 items). The measurements for mobile addiction were partly adapted from Negahban ${ }^{19}$, the use of SNS mobile applications (5 items) were adapted from Salehan and Negahban ${ }^{11}$, and SNS intensity ( 5 items) were borrowed from Ellison et al. ${ }^{20}$. These measurement items were designed in five-point Likert-type scales ranging from 1 (strongly disagree) to 5 (strongly agree).

The data was analyzed using Partial Least Square-Structural Equation Modelling (PLS-SEM) approach supported by SmartPLS 2.0 to assess the impact of the SNS intensity, the use of mobile social networking apps and mobile addiction.

\section{Data analysis}

Table 1 displays the descriptive statistics of the respondents' socio-demographic profiles. A total of 250 students are involved in the study, with more participations of female respondents $(52 \%)$ compared to the male respondents $(48 \%)$. The majority of the respondents $(80 \%)$ aged less than 21 years old. When asked about the frequency of using SNS mobile apps, the respondents report that they have access to the apps, less than twenty times in a day. Indeed, they mainly have less than 300 SNS friends and opt for Facebook than the competing SNS as a preference.

\subsection{Partial Least Square-Structural Equation Modelling}

The PLS-SEM approach was performed via a two-stage data analysis: measurement model and structural model. The measurement model was checked on the basis of the internal consistency reliability, convergent validity and discriminant validity of the measurement items. The reliability of the measurement items was tested via Cronbach's alpha and composite reliability.
Table 1: Demographic Profile of Respondents

\begin{tabular}{llcc}
\hline Variables & & Frequency & Percentage \\
\hline Gender & Male & 120 & 48.0 \\
Age (years old) & Female & 130 & 52.0 \\
& $\leq 19$ & 13 & 5.2 \\
& $20-21$ & 188 & 75.2 \\
& $22-23$ & 42 & 16.8 \\
Frequency of using SNS & $\geq 24$ & 7 & 2.8 \\
mobile apps in a day & $\leq 10$ & 35 & 14.0 \\
(times) & $11-15$ & 58 & 23.2 \\
\multirow{2}{*}{ Number of SNS friends } & $16-20$ & 113 & 45.2 \\
& $\geq 21$ & 44 & 17.5 \\
& $\leq 100$ & 63 & 25.2 \\
\multirow{5}{*}{ Most preferred SNS } & $101-300$ & 129 & 51.6 \\
& $301-500$ & 34 & 13.6 \\
& $\geq 501$ & 24 & 9.6 \\
& Facebook & 100 & 40.0 \\
& Twitter & 30 & 12.0 \\
& Instagram & 62 & 24.8 \\
& Tumblr & 6 & 2.4 \\
& YouTube & 52 & 20.8 \\
\hline
\end{tabular}

The results of Cronbach's alpha and composite reliability for all the variables are in excess of 0.70 (see Table 2), which is indicative of the solid reliability of the measures.

\begin{tabular}{|c|c|c|c|c|}
\hline Measurement items & Loadings & $\begin{array}{l}\text { Crophach's } \\
\text { alphas }\end{array}$ & $\mathrm{CR}$ & AVE \\
\hline \multicolumn{5}{|l|}{ SNS intensity } \\
\hline $\begin{array}{l}\text { Visiting social networking sites is part of my everyday } \\
\text { activity }\end{array}$ & 0.706 & 0.776 & 0.813 & 0.520 \\
\hline I check my social networking site(s) almost every day & 0.772 & & & \\
\hline I feel out of touch when I haven't logged onto my social & 0.704 & & & \\
\hline $\begin{array}{l}\text { I feel I am part of the community of my social networking } \\
\text { site at the campus }\end{array}$ & 0.701 & & & \\
\hline \multicolumn{5}{|l|}{ Use of SNS mobile apps } \\
\hline $\begin{array}{l}\text { I Uuse the social networking application(s) on my mobile } \\
\text { phone }\end{array}$ & 0.778 & 0.745 & 0.855 & 0.663 \\
\hline I use my mobile phone to log into my social network & 0.869 & & & \\
\hline I check my social networking site using my mobile phone & 0.793 & & & \\
\hline \multicolumn{5}{|l|}{ Mobile addiction } \\
\hline I feel lost when I do not have my mobile phone with me & 0.763 & 0.787 & 0.862 & 0.610 \\
\hline I am obsessed with my mobile phone & 0.737 & & & \\
\hline When I do not have my mobile phone I feel disconnected & 0.834 & & & \\
\hline I feel uneasy in places where mobile phone usage is & 0.788 & & & \\
\hline
\end{tabular}

The convergent validity of the measurement items was evaluated based on the analysis of the factor item loadings and average variance extracted (AVE). Preceding research asserted that convergent validity would be achieved if the factor item loadings are over and above $0.70^{21}$, and the AVE values are more than $0.50^{22}$. Table 2 indicates that all the factor item loadings surpass 0.70 and the AVE values are bigger than 0.50 which signify that the measurement items are well connoted by its respective variables. Nonetheless, four items are cast-off ahead of time because their loadings are underneath 0.70 .

Discriminant validity was evaluated by comparing the shared variance between the factors with the square root of the AVE of each construct $^{22}$. A satisfactory discriminant validity exists when the latter is larger than the first. Table 3 illustrates that the shared variance between the factors is lesser than the square root of the AVE of each construct, endorsing the discriminant validity. Likewise, all the correlation coefficients are under 0.70 , which uphold a satisfactory discriminant validity and the multicollinearity is elusive in this research ${ }^{23-24}$.

\begin{tabular}{|c|c|c|c|}
\hline Variables & SNS intensity & Use of SNS mobile apps & Mobile addiction \\
\hline SNS intensity & 0.721 & & \\
\hline Use of SNS mobile apps & $0.442^{8 *}$ & 0.814 & \\
\hline Mobile addiction & $0.570^{\mathrm{s*}}$ & $0.334^{* 8}$ & 0.781 \\
\hline $\begin{array}{l}\text { Mean } \\
\text { Standard deviation }\end{array}$ & $\begin{array}{l}3.888 \\
0.678\end{array}$ & $\begin{array}{l}4.250 \\
0.572\end{array}$ & $\begin{array}{l}3.696 \\
0.787\end{array}$ \\
\hline Skewneas & 0.878 & 0.720 & 0.611 \\
\hline Kurtosis & 1.938 & 0.248 & 0.155 \\
\hline
\end{tabular}

The structural model was performed to examine the impact between the independent variables (i.e. SNS intensity, and the use of SNS mobile apps) and the dependent variable (i.e. mobile addiction) in the research model by utilizing a bootstrapping resampling technique with 500 sub-samples. Table 4 displays the results of the path estimates and $t$-tests of the structural model. More pre- 
cisely, support is very strong for $\mathrm{H} 1$, which suggests that SNS intensity positively affects mobile addiction $\left(\beta_{1}=0.524\right.$, $t$ value $=16.055, p<0.05$ ).

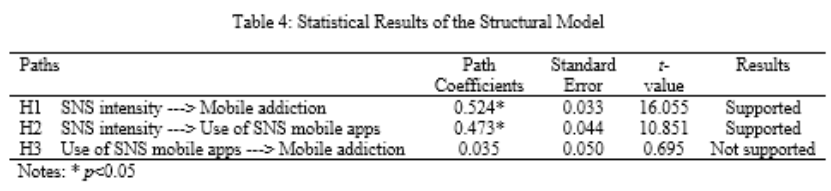

In a similar vein, SNS intensity has significantly and positively affected the use of the SNS mobile apps $\left(\beta_{2}=0.473 t\right.$-value $=10.851$, $p<0.05$ ), as postulated in $\mathrm{H} 2$. Hence, $\mathrm{H} 2$ is sustained. Further examination of the PLS path coefficient reveals that the use of SNS mobile apps have an insignificant impact on mobile addiction $\left(\beta_{3}=0.035 t\right.$-value $\left.=0.695, p>0.05\right)$. These results signify that $\mathrm{H} 3$ is rejected, which is not within expectations. The total variance of each endogenous construct explained by the model is $37 \%$ for mobile addiction and $32 \%$ for the use of SNS mobile apps. Thus, verifying the model's predictive validity.

\section{Discussion}

This research examined the predictors of mobile addiction. Via the PLS-SEM approach, this study provided empirical support for $\mathrm{H} 1$; there is a significant relationship between SNS intensity and mobile addiction. Users' have positively expressed that visiting SNS were part of their everyday activity as they tended to check their SNS almost every day. They perceive that they will feel out of touch when they do not log into their SNS for a day. In addition to that, they feel that they are part of the community of SNS on campus. These results are analogous to previous studies. For instance, Norazah $^{25}$ and Norazah and Norbayah ${ }^{26}$ avowed that users tended to feel lost and uneasy without having mobile phones with them over time as they treated the mobile phone as a significant belonging.

This study also recognized that SNS intensity had a significant and positive effect on the use of SNS mobile apps. Hence, H2 was upheld. The results implied that individuals with higher levels of SNS intensity have strong tendencies to install and use SNS mobile apps on their mobile phones to connect and communicate with others. Indeed, they heavily used their mobile phones to log into their social network via preferred social networking apps and actively checking SNS using their mobile phone. These findings supported prior research and are parallel to the outcome of Salehan and Negahban's ${ }^{11}$ research.

A closer inspection of the path estimated results of PLS reveals that $\mathrm{H} 3$ was not supported because the influence of the use of SNS mobile apps on mobile addiction was not significant. This result is incomparable with the results of prior work conducted by Salehan and Negahban ${ }^{11}$. Users' have articulated that they tend to feel lost if they do not carry their mobile phones with them all the time as they were strongly attached to their devices. Likewise, they also felt disconnected when the said situation aroused. Most importantly, they felt apprehensive when mobile phone usage is forbidden.

\section{Conclusions}

In a nutshell, when referring to the path estimates of the structural model, this empirical research provides evidence that SNS intensity is found as the strongest significant predictor of mobile addiction (see Figure 2).

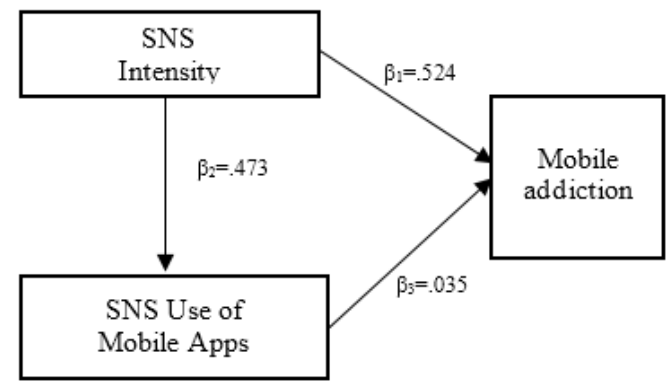

Figure 2: Results of Structural Model

In terms of the implication of this study, from academic perspectives, the present study adds to the understanding of the impact of SNS intensity to the users of SNS mobile apps on mobile addiction. It is suggested that for future research, the current research framework should be extended to include more constructs besides the moderating effects of gender. This can broaden our understanding of the mobile addiction among the male and female respondents. Earlier research documented that men are minimally addicted to mobile phones compared to women ${ }^{27}$.

\section{References}

[1] Facebook (2017). Facebook Reports Third Quarter 2017 Results. https://investor.fb.com/investor-news/press-releasedetails/2017/Facebook-Reports-Third-Quarter-2017Results/default.aspx

[2] EJ Pedrero Perez, MT Rodríguez Monje, JM Ruiz. Mobile phone abuse or addiction: A review of the literature. Adicciones, 24(2) (2012) 139-152.

[3] T Gao, J Li, H Zhang, J Gao, Y Kong, Y Hu, S Mei. The influence of alexithymia on mobile phone addiction: The role of depression, anxiety and stress. Journal of Affective Disorders, 225(2018) (2018) 761766.

[4] JB He, CR Chen, YC Bao, YJ Lei. A Probe into mobile phone dependence in adolescents: Measurement, harmfulness and genesis mechanism. Chinese Journal of Clinical Psychology, 20(6) (2012). 822-825.

[5] O Lopez-Fernandez, M Freixa-Blanxart. Prevalence of problematic mobile phone use in British adolescents. Cyberpsychology, Behavior, and Social Networking, 17(2), (2014) 91-98.

[6] L Chen, Z Yan, WJ Tang, FY Yang, XD Xie, JC He. Mobile phone addition levels and negative emotions among Chinese young adults: The mediating role of interpersonal problems. Computers in Human Behavior, 55(2016) (2016) 856-866.

[7] GS Dong, Y Park, KK Min, J Park. Mobile phone dependency and its impacts on adolescents' social and academic behaviors. Computers in Human Behavior, 63(2016) (2016) 282-292.

[8] A Belles, M Beranuy, X Carbonell, E Guardiola. A bibliometric analysis of the scientific literature on Internet, video games, and cell phone addiction. Journal of the Medical Library Association, 97(2) (2009) 102-107.

[9] Boyd, D. M., \& Ellison, N. B. (2008). Social network sites: Definition, history, and scholarship. Journal of Computer-Mediated Communication, $13(1), 210 \quad 230 . \quad$ http://dx.doi.org/10.1111/j.10836101.2007.00393.x.

[10] W Park. Mobile phone addiction. Mobile Communications, 31(xx) (2005) 253-272.

[11] M Salehan, A. Negahban. Social networking on smartphones: When mobile phones become addictive. Computers in Human Behavior, 29(6) (2013) 2632-2639.

[12] S Quinn, JA Oldmeadow. Is the igeneration a 'we'generation? Social networking use among 9-to 13-year-olds and belonging. British Journal of Developmental Psychology, 31(1) (2013) 136-142.

[13] CM Cheung, MK Lee. A theoretical model of intentional social action in online social networks. Decision Support Systems, 4 (1) (2010) 24-30.

[14] EK Clemons. The complex problem of monetizing virtual electronic social networks. Decision Support Systems, 48(1) (2009) 46-56. 
[15] X Zheng, MK Lee. Excessive use of mobile social networking sites: Negative consequences on individuals. Computers in Human Behavior, 5(10) (2016) 65-76.

[16] M Lyvers, SM Kohlsdorf, MS Edwards, FA Thorberg. Alexithymia and mood: recognition of emotion in self and others. American Journal of Psychology, 130(1) (2017) 83-92.

[17] A Nassehi, A Arbabisarjou, M Jafari, M Ghasemi, K Najafi. Surveying the relationship of Internet addiction with dependence on cell phone, depression, anxiety, and stress in collegians (Case Study: Bam University of Medical Sciences). International Journal of Advanced Biotechnology and Research, 7(3) (2016) 2267-2274.

[18] L Han, J Geng, M Jou, F Gao, H Yang. Relationship between shyness and mobile phone addiction in Chinese young adults: Mediating roles of self-control and attachment anxiety. Computers in Human Behavior, 76(2017) (2017) 363-371.

[19] A Negahban. Factors affecting individual's intention to purchase smartphones from technology adoption and technology dependence perspectives. Paper presented at the 18th Americas Conference on Information Systems, Seattle, WA. (2012).

[20] NB Ellison, C Steinfield, C Lampe. The benefits of Facebook "friends": Social capital and college students' use of online social network sites. Journal of Computer-Mediated Communication, 12(4) (2007) 1143-1168.

[21] JF Hair, B Black, B Babin, RE Anderson. Multivariate Data Analysis: A Global Perspective. Pearson Education Inc., New Jersey. (2010).

[22] C Fornell, DF Larcker. Evaluating structural equation models with unobservable variables and measurement error. Journal of Marketing Research, 18(1) (1981) 39-50.

[23] S Sussman, W Siegal. Informational influence in organizations: An integrated approach to knowledge adoption. Information Systems Research, 14(1) (2003) 47-65.

[24] BG Tabachnick, LS Fidell. Using Multivariate Statistics (5th ed.). Boston: Pearson/Allyn \& Bacon. (2007).

[25] MS Norazah. Correlations of perceived flow, perceived system quality, perceived information quality and perceived user trust on mobile social networking service (SNS) users' loyalty. Journal of Information Technology Research 5(2) (2012) 1-14

[26] MS Norazah, MS Norbayah. Mobile social networking service (sns) users' trust and loyalty: a structural approach. International Journal of Social Ecology and Sustainable Development, 7(3) (2016) 57-70.

[27] M Takao, S Takahashi, M Kitamura. Addictive personality and problematic mobile phone use. CyberPsychology \& Behavior, 12(5) (2009) 501-507. 